\title{
A Demonstração do Valor Adicionado - DVA como fonte de informações gerenciais: Um estudo em uma cooperativa de crédito
}

\author{
Jair Antonio Fagundes \\ Doutorando em Contabilidade, Universitat de Valencia, UV, Espanha. \\ Professor na FAHOR e FEMA \\ Rua Dr. Francisco Timm, 1840, Bairro Timbauva, 98.900-000, Santa Rosa - RS \\ jair@fema.com.br \\ Marcos Rogério Rodrigues \\ Mestrando em Administração na UNISINOS \\ Av. Rio Grande do Sul, 815 centro, 98.900-000, Santa Rosa-RS \\ marcos.110783@hotmail.com \\ Clébia Ciupak \\ Mestrado em Ciências Contábeis na UNISINOS (2007) \\ Professora Interina da UNEMAT e da Universidade de Cuiabá - UNIC - Sinop/MT \\ Rua dos Manacás, 2370, Str. Industrial, Sinop, MT \\ Clebia.ciupak@terra.com.br \\ Laura Sabbado da Rosa \\ Doutorando pela Universidade Pierre Mendès France (2007) \\ 8, Place Grenette 3ème étage, 38000 Grenoble, France \\ laura_sabbado@yahoo.com.br
}

O presente estudo objetiva apresentar a importância da Demonstração do Valor Adicionado (DVA) como ferramenta de análise gerencial em uma Cooperativa de Crédito Rural tomando por base o período de 19992006. Evidenciou-se a riqueza gerada pela entidade e, após a aplicação do método da adição, analisou-se o resultado do ponto de vista dos funcionários, do governo e dos associados. Estes resultados referem-se às informações coletadas nas Demonstrações Contábeis divulgadas pela Cooperativa, as quais serviram para a análise do período. O estudo realizado permitiu gerar várias informações que podem ser úteis a diversos usuários, pois houve o acréscimo de mais uma ferramenta de suporte ao gerenciamento e tomada de decisões, de vez que até então as análises tinha unicamente como parâmetro os valores expressos nas Demonstrações de Resultados do Exercício.

Palavras-chave: Demonstração do Valor Adicionado, Cooperativas de Crédito, Demonstrações Contábeis, Evidenciação Contábil.

The demonstration of the value added - DVA as source of information managerial: A study in a cooperative of credit

The present study main to show the importance of Demonstration of Value Added (DVA) how tool of managerial analysis in a cooperative of agricultural credit tend by base the period of 1999-2006. It was evidence the richness generated by entity and, after the application of the method of the addition, it was analyzed the outcome of the point of view of the employees, the government and the associates. These outcomes referred the information collected in the account demonstration published by cooperative, which assisted for the analysis of the period. The study allowed generating some information that can be useful the some users, as had the addition of the more a tool of support to the management and decision maker, of turn that until then the analysis had only as parameter the express values in the demonstration of outcome of exercise.

Key Words: demonstration of the value added, credit cooperative, accounting demonstration, accounting evidence. 
A Demonstração do Valor Adicionado (DVA) como fonte de informações gerenciais: Um estudo em uma cooperativa de crédito.

Jair Antonio Fagundes, Marcos Rogério Rodrigues, Clébia Ciupak, Laura Sabbado da Rosa.

mesma deverá equilibrar essa dupla característica - o aspecto social e o econômico, buscando sempre o aperfeiçoamento de suas atividades e sua filosofia.

De acordo com Sicredi (2006), o sistema cooperativo se configura como um sistema capaz de encorajar e estimular a participação ativa da população na realização de programas de desenvolvimento. No Brasil foram feitas três tentativas de implantação do sistema sem lograr êxito; duas no Paraná e uma em Pernambuco. Em 1902, no entanto, por iniciativa do Padre Suíço, o Jesuíta Theodor Amstadt, o Rio Grande do Sul tornou-se o berço do Cooperativismo Nacional, com a implantação da Caixa Rural Cooperativa de Nova Petrópolis - RS.

O padre Amstadt percorreu durante vários anos as colonizações, e além de prestar assistência espiritual pregou a doutrina do sistema de crédito cooperativista, expandindo o cooperativismo por todo o Estado e País. Porém com a lei 22.239 de 1932, que decretava o cumprimento dos fundamentos do cooperativismo em nosso meio a expansão do sistema acelerou-se, ganhando maior força, principalmente no estado do Rio Grande do Sul e São Paulo, pois foram os dois estados que receberam maior fluxo de imigrantes europeus, que já conheciam as vantagens do sistema em suas terras de origem.

$\mathrm{Na}$ atualidade as cooperativas estão atuando nas mais diversas atividades, com mais intensidade em alguns setores que em outros, estando mais fortalecidas dentro do sistema financeiro. De forma geral, estão contribuindo, significativamente, com a organização da estrutura social e econômica do País, buscando um desenvolvimento mais democrático, igualitário e humano, baseando-se no exercício da cidadania (Sicredi, 2006).

O cooperativismo de crédito tem como princípio básico, a concessão de empréstimos individuais baseados em poupança coletiva, na promoção da educação econômica e financeira dos seus cooperados e no estabelecimento da poupança sistemática, chegando atualmente à prestação de serviços bancários completos. Além disso, os recursos captados pelas cooperativas de crédito são aplicados no seu local de origem, aumentando a produção e atendendo aos fins sociais decididos pelos associados, baseados nos interesses comunitários.

Ressalta-se que independente do gênero de serviço da cooperativa, a mesma está sempre voltada para o associado, para o auto-desenvolvimento e auto-gerenciamento, visando não oferecer riscos a terceiros, pois suas sobras e prejuízos são democraticamente rateados entre os associados. 
A Demonstração do Valor Adicionado (DVA) como fonte de informações gerenciais: Um estudo em uma cooperativa de crédito.

Jair Antonio Fagundes, Marcos Rogério Rodrigues, Clébia Ciupak, Laura Sabbado da Rosa.

\section{Balanço social e a demonstração do valor adicionado}

O Balanço Social surgiu na Europa com o objetivo de atender aos movimentos sociais que demandavam informações sobre projetos sociais, condições ambientais, informações para os empregados sobre o nível de emprego, condições de trabalho, remuneração e formação profissional.

A Demonstração do Valor Adicionado surgiu por influência da França e da Alemanha, como forma de mensuração desta participação da empresa neste contexto social. No Brasil, o conceito de Balanço Social foi difundido pelo professor Tinoco em 1984, ao defender a sua dissertação de mestrado, e um dos principais divulgadores do balanço Social foi o Sociólogo Herbert de Souza que criou em 1981 o Instituto Brasileiro de Análises Sociais e Econômicas (IBASE).

Um importante componente do Balanço Social é justamente a Demonstração do Valor Adicionado, que tem como objetivo demonstrar o desempenho econômico da empresa e seu relacionamento com a sociedade. A Demonstração do Valor Adicionado evidencia o valor agregado durante o seu processo produtivo ampliando e a forma de sua distribuição aos grupos de interesse.

De acordo com Tinoco (2001, p. 64), uma das formas de se analisar o desempenho financeiro de uma empresa pode ser "pelo valor econômico que é agregado aos bens e serviços adquiridos", denominado pelo autor de "valor adicionado ou valor agregado (DVA). Segundo Rodrigues (1995), Oliveira e Garcia (2000) e Santos e Hashimoto (2003), a DVA vem sendo considerada como um dos critérios que melhor indicam a medida da eficácia da gestão empresarial".

Tinoco (2001, p. 65) apresenta uma idéia simplificada de valor adicionado, ou seja: "vendas compras = valor adicionado bruto". O autor apresenta um exemplo de valor adicionado, onde, primeiramente, aparece a demonstração do resultado de um determinado período e, em seguida, a configuração da DVA deste mesmo período: 
A Demonstração do Valor Adicionado (DVA) como fonte de informações gerenciais: Um estudo em uma cooperativa de crédito.

Jair Antonio Fagundes, Marcos Rogério Rodrigues, Clébia Ciupak, Laura Sabbado da Rosa.

Tabela 01 - Demonstração do Resultado

\begin{tabular}{|lc|}
\hline & Demonstração do Resultado \\
\hline + Vendas & $\mathrm{R} \$ 10.000,00$ \\
\hline - Mão-de-obra & $\mathrm{R} \$ 5.000,00$ \\
\hline - Juros & $\mathrm{R} \$ 2.000,00$ \\
\hline = lucro & $\mathrm{R} \$ 3.000,00$ \\
\hline
\end{tabular}

Fonte: Tinoco (2001, p. 65).

Tabela 02 - Demonstração do Valor Adicionado

\begin{tabular}{|lccc|}
\hline \multicolumn{4}{|c|}{ Demonstração do Valor Adicionado } \\
\hline Mão-de-obra & $\mathrm{R} \$$ & $5.000,00$ & $50 \%$ \\
\hline Remuneração capital de terceiros & $\mathrm{R} \$$ & $2.000,00$ & $20 \%$ \\
\hline Remuneração capital próprio & $\mathrm{R} \$$ & $3.000,00$ & $30 \%$ \\
\hline Total adicionado & $\mathrm{R} \$$ & $10.000,00$ & $100 \%$ \\
\hline
\end{tabular}

Fonte: Tinoco (2001, p. 65).

Kroetz (2000, p. 41) menciona outro exemplo, o qual é demonstrado na Tabela 3:

Tabela 03 - Geração de Riqueza

\begin{tabular}{l|r}
\hline Geração de riqueza & X01 \\
\hline Geração do valor adicionado & 37.096 .446 \\
Receita de serviços & 36.785 .893 \\
Receitas não operacionais & 310.553 \\
\hline Musto $\quad$ & 7.620 .155 \\
$\quad$ Serviços de terceiros e outros & 5.305 .198 \\
Valor adicionado bruto (a - b) & 2.314 .957 \\
\hline Depreciações & 29.476 .291 \\
\hline Receita Financeira & 3.201 .595 \\
\hline Valor adicionado a distribuir (c-d+e) & 352.796 \\
\hline
\end{tabular}

Fonte - Kroetz, (2000, p. 41).

A Tabela 03 demonstra o valor adicionado a distribuir no exercício 'x 01'; com o que é possível compor a demonstração da distribuição de riqueza demonstrada na Tabela 04.

Tabela 04 - Distribuição de Riqueza Gerada no período de "X 01"

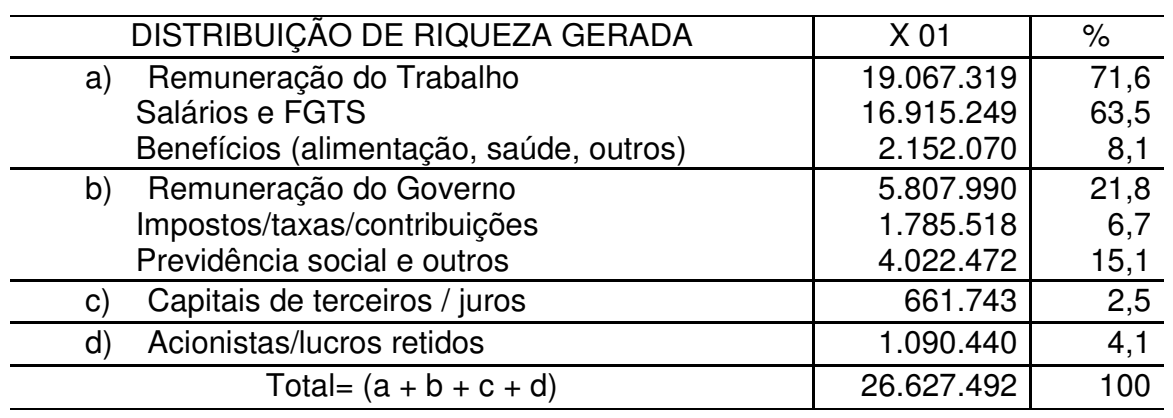

Fonte - Kroetz, (2000, p. 41). 
A Demonstração do Valor Adicionado (DVA) como fonte de informações gerenciais: Um estudo em uma cooperativa de crédito.

Jair Antonio Fagundes, Marcos Rogério Rodrigues, Clébia Ciupak, Laura Sabbado da Rosa.

Esta tabela mostra um exemplo de como a DVA pode ser utilizada para o gerenciamento dos resultados obtidos pela empresa em determinados períodos. Ela se estrutura em três colunas: descrição das rubricas; valor em reais e distribuição em percentual da riqueza gerada com dados de um determinado período (x01). Estes demonstram quais foram os valores e percentuais distribuídos e para quem foram distribuídos.

O Conselho Federal de Contabilidade, através da Resolução no 1010 de 19/11/2004, aprovou a NBC T 3.7 sobre as regras de evidenciação da Demonstração do Valor Adicionado - DVA.

\subsection{Metodologia de Determinação do Valor Adicionado}

De acordo com Cosenza (2003), o cálculo do valor adicionado pode ser utilizado sob dois enfoques: o enfoque contábil e o enfoque econômico. Na área econômica, o conceito de riqueza gerada é obtido a partir do montante da produção, enquanto no primeiro enfoque, o contábil, pode-se evidenciar com base no montante das vendas. Neste trabalho, será utilizado o enfoque contábil, por se dispor do valor das vendas através expresso na Demonstração do Resultado do Exercício DRE.

Existem dois métodos para a determinação do cálculo do valor adicionado: o método da Adição e o método da Subtração. O primeiro agrega uma série de rendas que acumulam os lucros ou sobras derivadas da atividade organizacional, como exemplo a seguir:

Tabela 05 - Esquema do Método de Adição

\begin{tabular}{lrr}
\hline COMPONENTES & $\mathrm{R} \$$ Mil & $\%$ \\
\hline + Gastos com pessoal & 450.000 & 7,4 \\
+ Gastos financeiros & 780.000 & 12,8 \\
+ Tributos e impostos sobre lucros & 120.000 & 2,0 \\
+ Depreciação, Amortização, Exaustão e Provisões & 3.450 .000 & 56,5 \\
+ Lucros ou Prejuízos do Exercício (saldo DRE antes da destinação dos lucros) & 1.304 .000 & 21,4 \\
= VALOR ADICIONADO BRUTO EMPRESARIAL & 6.104 .000 & 100,0 \\
(-)Depreciação, Amortização, Exaustão e Provisões & $(3.450 .000)$ & $(56,5)$ \\
\hline = VALOR ADICIONADO LÍQUIDO EMPRESARIAL & 2.654 .000 & 43,5
\end{tabular}

Fonte - Cozensa (2003, p.12).

O método da Subtração pode ser calculado a partir da soma de todos os fluxos positivos procedentes das atividades empresariais, deduzidos dos consumos 
A Demonstração do Valor Adicionado (DVA) como fonte de informações gerenciais: Um estudo em uma cooperativa de crédito.

Jair Antonio Fagundes, Marcos Rogério Rodrigues, Clébia Ciupak, Laura Sabbado da Rosa.

intermediários derivados das entregas dos bens ou prestações de serviços de terceiros. Um exemplo de DVA, em que são distribuídos os grupos ou contas e seus respectivos valores em consonância com o método da subtração e enfoque contábil, é apresentado na Tabela 06.

Tabela 06 - DVA da Cooperativa de Crédito Rural Santa Rosa dos anos 2001, 2002 e 2003 pelo Método da Subtração e Enfoque Contábil

\begin{tabular}{lcccccc}
\hline & 2003 & AV\% & 2002 & AV\% & 2001 & AV\% \\
1) RECEITAS TOTAIS & $\mathbf{1 6 . 2 7 7 . 3 5 4}$ & $\mathbf{1 0 0 , 0 0 \%}$ & $\mathbf{1 1 . 5 1 0 . 4 2 5}$ & $\mathbf{1 0 0 , 0 0 \%}$ & $\mathbf{7 . 7 8 3 . 7 5 1}$ & $\mathbf{1 0 0 , 0 0}$ \\
\hline 1.1) Intermediação financeira & 9.821 .371 & 60,34 & 7.169 .204 & 62,28 & 5.397 .701 & 69,35 \\
1.2) Prestação de Serviços & 1.410 .439 & 8,67 & 1.104 .768 & 9,60 & 803.793 & 10,33 \\
1.3) Receitas operacionais & 5.099 .372 & 31,33 & 3.223 .069 & 28,00 & 1.570 .845 & 20,18 \\
1.4) Não operacionais & $(53.828)$ & $-0,33$ & 13.384 & 0,12 & 11.412 & 0,15 \\
2) CUSTOS & $\mathbf{7 . 8 3 7 . 6 0 0}$ & $\mathbf{4 8 , 1 5}$ & $\mathbf{4 . 8 6 5 . 6 6 2}$ & $\mathbf{4 2 , 2 7 \%}$ & $\mathbf{3 . 5 9 5 . 5 1 9}$ & $\mathbf{4 6 , 1 9}$ \\
2.1) Intermediação financeira & 7.837 .600 & 48,15 & 4.865 .662 & 42,27 & 3.595 .519 & 46,19 \\
3) VALOR ADICIONADO BRUTO & $\mathbf{8 . 4 3 9 . 7 5 4}$ & $\mathbf{5 1 , 8 5}$ & $\mathbf{6 . 6 4 4 . 7 6 3}$ & $\mathbf{5 7 , 7 3}$ & $\mathbf{4 . 1 8 8 . 2 3 2}$ & $\mathbf{5 3 , 8 1}$ \\
4) DESPESAS & $\mathbf{3 . 3 2 5 . 8 1 7}$ & $\mathbf{2 0 , 4 3}$ & $\mathbf{2 . 6 8 4 . 4 3 9}$ & $\mathbf{2 3 , 3 2}$ & $\mathbf{1 . 3 6 4 . 0 6 8}$ & $\mathbf{1 7 , 5 2}$ \\
4.1) Despesas Administrativas & 2.315 .087 & 14,22 & 1.611 .658 & 14,00 & 1.122 .763 & 14,42 \\
4.2) Despesas Operacionais & 1.010 .730 & 6,21 & 1.072 .781 & 9,32 & 241.305 & 3,10 \\
5) VALOR ADICIONADO & & & & & \\
LíQUIDO & $\mathbf{5 . 1 1 3 . 9 3 7}$ & $\mathbf{3 1 , 4 2}$ & $\mathbf{3 . 9 6 0 . 3 2 4}$ & $\mathbf{3 4 , 4 1}$ & $\mathbf{2 . 8 2 4 . 1 6 4}$ & $\mathbf{3 6 , 2 8}$ \\
6) DEMONSTRAÇÃO VALOR & & & & & & \\
ADICIONADO & $\mathbf{5 . 1 1 3 . 9 3 7}$ & $\mathbf{1 0 0 , 0 0}$ & $\mathbf{3 . 9 6 0 . 3 2 4}$ & $\mathbf{1 0 0 , 0 0}$ & $\mathbf{2 . 8 2 4 . 1 6 4}$ & $\mathbf{1 0 0 , 0 0}$ \\
6.1) GOVERNO & $\mathbf{1 2 5 . 5 5 5}$ & $\mathbf{2 , 4 6}$ & $\mathbf{2 9 . 3 0 5}$ & $\mathbf{0 , 7 4}$ & $\mathbf{2 2 . 9 3 0}$ & $\mathbf{0 , 8 1}$ \\
5.1.1) Despesas Tributárias & 88.858 & 1,74 & 25.354 & 0,64 & 19.960 & 0,71 \\
5.1.2) IR e CSLL & 36.697 & 0,72 & 3.951 & 0,10 & 2.970 & 0,11 \\
6.2) FUNCIONÁRIOS & $\mathbf{2 . 9 5 2 . 5 1 4}$ & $\mathbf{5 7 , 7 3}$ & $\mathbf{2 . 0 5 4 . 2 5 7}$ & $\mathbf{5 1 , 8 7}$ & $\mathbf{1 . 4 7 6 . 8 7 4}$ & $\mathbf{5 2 , 2 9}$ \\
5.2.1) Despesas com pessoal & 2.952 .514 & 57,73 & 2.054 .257 & 51,87 & 1.476 .874 & $\mathbf{5 2 , 2 9}$ \\
6.3) ASSOCIADOS & $\mathbf{2 . 0 3 5 . 8 6 8}$ & $\mathbf{3 9 , 8 1}$ & $\mathbf{1 . 8 7 6 . 7 6 2}$ & $\mathbf{4 7 , 3 9}$ & $\mathbf{1 . 3 2 4 . 3 6 0}$ & $\mathbf{4 6 , 8 9}$ \\
\hline 5.3.1) Sobras & 2.035 .868 & 39,81 & 1.876 .762 & 47,39 & 1.324 .360 & $\mathbf{4 6 , 8 9}$ \\
\hline
\end{tabular}

Fonte: Fagundes e Kuhn (2004).

Este método tem gerado algumas dificuldades no seu preenchimento. Entre elas, a dificuldade enfrentada pelas empresas no que diz respeito à separação dos itens que compõem o custo dos produtos vendidos. No entanto, é também o método que apresenta um maior nível de detalhamento da informação, facilitando o processo decisório.

Ao se pretender utilizar o DVA como um relatório gerencial, alguns inconvenientes se apresentam devido à falta de padronização, o que pode gerar controvérsias em relação ao cálculo do valor adicionado. Entre estas, pode-se citar o tratamento contábil utilizado para o registro de operações, dificultando a análise comparativa entre diversas empresas. Alguns pontos positivos e negativos da DVA no Quadro 1: 
A Demonstração do Valor Adicionado (DVA) como fonte de informações gerenciais: Um estudo em uma cooperativa de crédito.

Jair Antonio Fagundes, Marcos Rogério Rodrigues, Clébia Ciupak, Laura Sabbado da Rosa.

\begin{tabular}{|c|c|}
\hline PONTOS POSITIVOS & \\
\hline $\begin{array}{l}\text { Permite obter uma dupla visão da realidade } \\
\text { empresarial: a econômica, relativa ao valor gerado, } \\
\text { e a social, correspondente às rendas distribuídas. }\end{array}$ & $\begin{array}{l}\text { Apresenta dificuldades de entendimento por causa } \\
\text { de sua não normatização e estandardização. }\end{array}$ \\
\hline $\begin{array}{l}\text { Possibilita desenvolver um efetivo sistema de } \\
\text { avaliação dos gestores e unidades. }\end{array}$ & $\begin{array}{l}\text { Pode levar à tomada de decisões incorretas quanto } \\
\text { à maximização do valor adicionado, em lugar dos } \\
\text { lucros. }\end{array}$ \\
\hline $\begin{array}{l}\text { Tem uma linguagem aceita por todos os seus } \\
\text { destinatários e que se faz compreensível ao } \\
\text { conhecimento de qualquer usuário. }\end{array}$ & $\begin{array}{l}\text { Está sujeita à incorporação de distorções } \\
\text { provocadas por sua subjetividade e forma própria } \\
\text { de estimativa. }\end{array}$ \\
\hline $\begin{array}{l}\text { Reflete a lucratividade e a eficiência das operações } \\
\text { e atividades da entidade, como também a evolução } \\
\text { econômica em seu conjunto. }\end{array}$ & $\begin{array}{l}\text { ar uma certa dificuldade na } \\
\text { análises de desempenho emp } \\
\text { imico a que a companhia perte }\end{array}$ \\
\hline $\begin{array}{l}\text { Fornece dados para a tomada de decisão e o } \\
\text { sistema de controle de desempenho. }\end{array}$ & $\begin{array}{l}\text { de informações contábeis atu } \\
\text { e, se possível, auditadas. }\end{array}$ \\
\hline $\begin{array}{l}\text { Permite conhecer a contribuição econômica da } \\
\text { empresa para a renda nacional ou para seu } \\
\text { ambiente econômico ou social. }\end{array}$ & $\begin{array}{l}\text { Pode ser demasiadamente trabalhoso em } \\
\text { ambientes de grandes incertezas e complexidades } \\
\text { monetárias, tributárias e econômicas. }\end{array}$ \\
\hline & $\begin{array}{l}\text { É limitada para medir e informar a efi } \\
\text { alcançada na distribuição social dos lucros ger }\end{array}$ \\
\hline
\end{tabular}

Quadro 01 - Pontos positivos e negativos da DVA

Fonte - Cozensa (2003, p.16).

\section{Estudo Sobre DVA na Sicredi Grande Santa Rosa}

De acordo com dados extraídos do Manual do Colaborador publicado pela a Cooperativa de Crédito de Livre Admissão de Associados Grande Santa Rosa (2002), filiada ao sistema Sicredi, esta se caracteriza por ser uma sociedade de pessoas que integra o sistema financeiro nacional. A cooperativa foi fundada em 23 de junho de 1981, com a denominação de Cooperativa de Crédito Rural Santa Rosa Ltda (Credirosa), tendo inicialmente 25 associados, os quais foram apoiados pela Cooperativa Tritícola Santa Rosa Ltda (Cotrirosa). Em 1985 firmou convênio com o Banco Nacional de Crédito Cooperativo (BNCC) para a compensação de cheques o qual foi substituído pelo Banco do Brasil a partir de 1990.

Desde sua fundação, os avanços foram significativos, apesar das dificuldades, a busca por novos associados sempre foi constante, já que o cooperativismo de crédito busca auxiliar no crescimento das comunidades. A partir de 1992 houve uma reestruturação e a cooperativa passou a utilizar a denominação de Sicredi Santa Rosa. No ano de 1996, outra mudança que caracterizou o crescimento da cooperativa foi à incorporação da Cooperativa de Crédito Rural Tucunduva (Credituva), o que ampliou a área de atuação, proporcionando novos negócios, e contribuindo para o desenvolvimento da região. 
A Demonstração do Valor Adicionado (DVA) como fonte de informações gerenciais: Um estudo em uma cooperativa de crédito.

Jair Antonio Fagundes, Marcos Rogério Rodrigues, Clébia Ciupak, Laura Sabbado da Rosa.

Em 2000 também foi incorporada ao sistema uma corretora de valores, administradora de cartões de crédito e uma confederação; a Sicredi serviços, responsável pela interligação on-line dos postos de atendimento do Sistema Sicredil nos estados em que atua: MS, MT, PR, RS, SC, SP e GO. No ano de 2004, a Sicredi Santa Rosa dá um passo importante, conquista a Livre Admissão de Associados, passando a associar pessoas e empresas de todos os segmentos do mercado. Com esta mudança, passa a denominarse Sicredi Grande Santa Rosa.

De acordo com as informações contidas na homepage do Sicredi Grande Santa Rosa (2006), esta tem como visão ser reconhecida pela sociedade como instituição cooperativa com excelência operacional e de gestão. Para tanto, as Cooperativas de Crédito do Sistema Sicredi atuam na captação, administração e empréstimo de recursos financeiros e prestação de serviços, agregando renda aos seus associados.

Atualmente a Sicredi Santa Rosa atua na região da grande Santa Rosa, nos municípios de: Alecrim, Campina das Missões, Cândido do Godói, Giruá, Novo Machado, Porto Lucena, Porto Mauá, Santa Rosa, Santo Cristo, Senador Salgado Filho, Tucunduva e Tuparendi.

\subsection{Análise Financeira e Social da DVA as Sicredi Grande Santa Rosa}

Como já mencionado anteriormente, a análise da DVA abrange dados financeiros que podem proporcionar uma avaliação da participação de uma organização na economia de seu Município, Estado e País, pois apresenta de forma diferenciada dos demais relatórios contábeis os valores destinados em um determinado período para seus colaboradores, para as administrações públicas, associados e ainda os investimentos no seu próprio desenvolvimento, que podem possibilitar geração de riqueza futura.

Valor agregado ou adicionado é todo custo, despesa ou resultado, que proporcionará a continuidade na geração de riquezas para a comunidade com a sua movimentação, como por exemplo, os valores recebidos a título de remuneração pelo trabalho que podem ser utilizados pelos colaboradores na aquisição de bens e serviços, gerando novas riquezas em outras organizações, proporcionando com isto, o desenvolvimento da sociedade. 
A Demonstração do Valor Adicionado (DVA) como fonte de informações gerenciais: Um estudo em uma cooperativa de crédito.

Jair Antonio Fagundes, Marcos Rogério Rodrigues, Clébia Ciupak, Laura Sabbado da Rosa.

Sob esse enfoque, elaborou-se e analisou-se os resultados da DVA da Cooperativa de Crédito de Livre Admissão de Associados Grande Santa Rosa (Sicredi) no período de 1999 a 2006, com base nas DREs dos respectivos anos, destacando que os resultados foram obtidos com a aplicação do método da adição e com enfoque contábil.

Para melhor analisar e evidenciar utilizou-se também outra técnica de análise das demonstrações contábeis, ou seja, "a determinação da porcentagem de cada conta ou de grupo de contas em relação ao seu conjunto" (Ribeiro, 1999, p. 117).

A Tabela 07 reflete a DVA de acordo com o método da adição, proposto por Cosenza (2003), da Cooperativa de Crédito no período de 1999 a 2006, bem como análise vertical. Esta evidenciação permite a análise de forma individual (estrutural) e comparativa (entre os anos do período analisado) 
A Demonstração do Valor Adicionado (DVA) como fonte de informações gerenciais: Um estudo em uma cooperativa de crédito. Jair Antonio Fagundes, Marcos Rogério Rodrigues, Clébia Ciupak, Laura Sabbado da Rosa.

Tabela 7 - Demonstração do Valor Adicionado com análise vertical de 1999 a 2006.

\begin{tabular}{|c|c|c|c|c|c|c|c|c|c|c|c|c|c|c|c|c|}
\hline & 2006 & AV \% & 2005 & AV \% & 2004 & AV \% & 2003 & AV \% & 2002 & AV \% & 2001 & AV \% & 2000 & AV \% & 1999 & AV \% \\
\hline $\begin{array}{l}\text { 1) } \\
\text { DEMONSTRAÇÃO } \\
\text { VALOR } \\
\text { ADICIONADO }\end{array}$ & 8.524 .955 & 100,00 & 6.676 .481 & 100,00 & 6.633 .347 & 100,00 & 5.113 .937 & 100,00 & 3.960 .324 & 100,00 & 2.824 .164 & 100,00 & 1.944 .847 & 100,00 & 2.028.759 & 100,00 \\
\hline 1.1) GOVERNO & 450.399 & 5,28 & 232.208 & 3,48 & 151.368 & 2,28 & 125.555 & 2,46 & 29.305 & 0,74 & 22.930 & 0,81 & 13.429 & 0,69 & 13.842 & 0,68 \\
\hline $\begin{array}{l}\text { 1.1.1) Despesas } \\
\text { Tributárias }\end{array}$ & 182.117 & 2,14 & 81.158 & 1,22 & 102.900 & 1,55 & 88.858 & 1,74 & 25.354 & 0,64 & 19.960 & 0,71 & 11.895 & 0,61 & 9.502 & 0,47 \\
\hline 1.1.2) IR e CSLL & 268.282 & 3,15 & 151.050 & 2,26 & 48.468 & 0,73 & 36.697 & 0,72 & 3.951 & 0,10 & 2.970 & 0,11 & 1.534 & 0,08 & 4.340 & 0,21 \\
\hline $\begin{array}{l}\text { 1.2) } \\
\text { FUNCIONÁRIOS }\end{array}$ & 5.428 .559 & 63,68 & 4.199.216 & 62,90 & 3.769 .562 & 56,83 & 2.952 .514 & 57,73 & 2.054.257 & 51,87 & 1.476 .874 & 52,29 & 1.129 .593 & 58,08 & 965.044 & 47,57 \\
\hline $\begin{array}{l}\text { 1.2.1) Despesas } \\
\text { com pessoal }\end{array}$ & 5.428 .559 & 63,68 & 4.199.216 & 62,90 & 3.769 .562 & 56,83 & 2.952 .514 & 57,73 & 2.054 .257 & 51,87 & 1.476 .874 & 52,29 & 1.129 .593 & 58,08 & 965.044 & 47,57 \\
\hline 1.3) ASSOCIADOS & 2.645 .997 & 31,04 & 2.245 .057 & 33,63 & 2.712.417 & 40,89 & 2.035.868 & 39,81 & 1.876 .762 & 47,39 & 1.324 .360 & 46,89 & 801.825 & 41,23 & 1.049 .873 & 51,75 \\
\hline $\begin{array}{l}\text { 1.3.1) Sobras antes } \\
\text { das destinações }\end{array}$ & 2.645 .997 & 31,04 & 2.245 .057 & 33,63 & 2.712.417 & 40,89 & 2.035 .868 & 39,81 & 1.876 .762 & 47,39 & 1.324 .360 & 46,89 & 801.825 & 41,23 & 1.049 .873 & 51,75 \\
\hline
\end{tabular}

Fonte - Cooperativa de Crédito de Livre Admissão de Associados Grande Santa Rosa 
A Demonstração do Valor Adicionado (DVA) como fonte de informações gerenciais: Um estudo em uma cooperativa de crédito.

Jair Antonio Fagundes, Marcos Rogério Rodrigues, Clébia Ciupak, Laura Sabbado da Rosa.

O Gráfico 1, em conjunto com a Tabela 07, evidenciam o valor adicionado de cada um dos três itens que compõe o Valor Adicionado - VA da entidade. Percebe-se o constante aumento na distribuição deste VA aos funcionários (de $R \$ 965.044,00$ em 1999 para $R \$ 5.428 .559,00$ em 2006), ao governo (de $R \$ 13.842,00$ em 1999 para $R \$ 450.399,00$ em 2006).

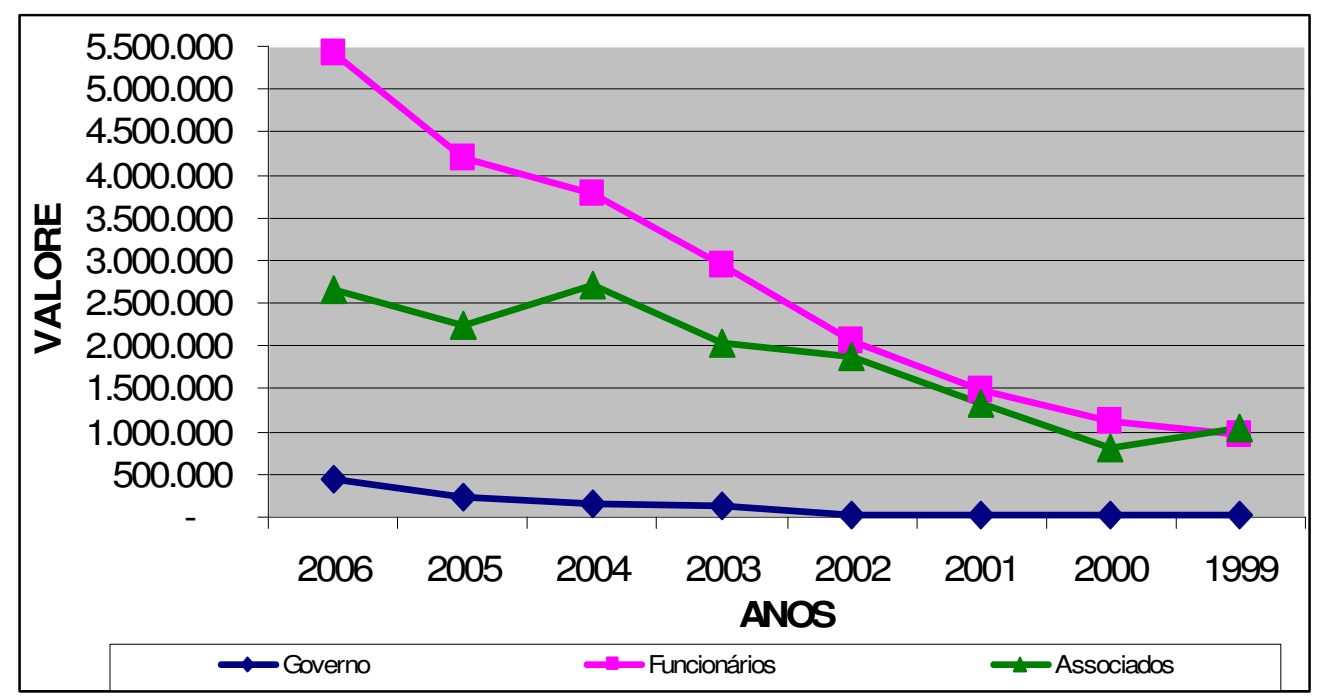

Gráfico 1 - Evolução do valor adicionado de 1999 a 2006.

Fonte - Cooperativa de Crédito de Livre Admissão de Associados Grande Santa Rosa

O aumento na distribuição d riqueza gerada pela cooperativa para os funcionários, governos e associados, demonstra a sua importância financeira e social na comunidade, pois através dos salários pagos aos funcionários estes possivelmente gastem na própria comunidade onde está inserida a cooperativa, gerando assim um efeito imediato na sociedade local; também no recolhimento dos impostos ao governo (em ambos os níveis), há uma contribuição da cooperativa na redistribuição em formato de ações sociais para os cidadãos brasileiros, e na distribuição das sobras aos associados, estes têm a possibilidade de reinvestir estes valores no capital social da cooperativa, contribuindo para o seu fortalecimento.

Tabela 8 - Análise Vertical do VA destinado aos Governos, Funcionários e Associados com base no Valor Adicionado Total no período de 1999 a 2006.

\begin{tabular}{|c|c|c|c|c|c|c|c|c|}
\hline ANO $=>$ & 2006 & 2005 & 2004 & 2003 & 2002 & 2001 & 2000 & 1999 \\
\hline $\begin{array}{l}\text { VA governo: } \\
\text { variação (AV\%) }\end{array}$ & $5,28 \%$ & $3,48 \%$ & $2,28 \%$ & $2,46 \%$ & $0,74 \%$ & $0,81 \%$ & $0,69 \%$ & $0,68 \%$ \\
\hline $\begin{array}{l}\text { VA funcionários: } \\
\text { variação (AV\%) }\end{array}$ & $63,68 \%$ & $62,90 \%$ & $56,83 \%$ & $57,73 \%$ & $51,87 \%$ & $52,29 \%$ & $58,08 \%$ & $47,57 \%$ \\
\hline $\begin{array}{l}\text { VA associados: } \\
\text { variação (AV\%) }\end{array}$ & $31,04 \%$ & $33,63 \%$ & $40,89 \%$ & $39,81 \%$ & $47,39 \%$ & $46,89 \%$ & $41,23 \%$ & $51,75 \%$ \\
\hline
\end{tabular}

Fonte - Cooperativa de Crédito de Livre Admissão de Associados Grande Santa Rosa 
A Demonstração do Valor Adicionado (DVA) como fonte de informações gerenciais: Um estudo em uma cooperativa de crédito.

Jair Antonio Fagundes, Marcos Rogério Rodrigues, Clébia Ciupak, Laura Sabbado da Rosa.

A tabela 8 e o Gráfico 2 evidenciam a evolução dos percentuais dos três itens que compõem o Valor Adicionado da entidade. Percebe-se o constante aumento na participação dos funcionários (de 47,57\% em 1999 para 63,68\% em 2006) e do governo (de 0,68\% em 1999 para 5,28\% em 2006) e redução na participação dos associados (de 51,75\% em 1999 para 31,04\% em 2006).

Nem sempre os aumentos no valor absoluto das sobras aos associados significam aumento na participação do valor adicionado, pois, enquanto existe um aumento neste valor absoluto a análise vertical revela um caminho contrário quando comparado com os anos anteriores e também aos demais itens do valor adicionado, ou seja, houve aumento absoluto de $\mathrm{R} \$$ 1.049.873,00 em 1999 para $R \$ 2.645 .997$ em 2006 e percentualmente a evolução é contrária, ou seja, houve redução nesta participação de 51,75\% em 1999 para 31,04\% em 2006.

Já para os funcionários houve aumento absoluto e percentual no período analisado (de 47,57\% em 1999 para 63,68\% em 2006) e (de $R \$ 965.044,00$ em 1999 para $R \$ 5.428 .559,00$ em 2006). Este aumento pode ser proveniente de aumentos nos salários, aumento do quadro de pessoal, entre outros.

E quanto ao governo também houve aumento absoluto e percentual (de 0,68\% em 1999 para $5,28 \%$ em 2006) e (de $R \$ 13.842,00$ em 1999 para $R \$ 450.399,00$ em 2006), demonstrando assim um grande aumento na distribuição de riqueza, cabendo analisar os motivos que influenciaram nesta grande variação.

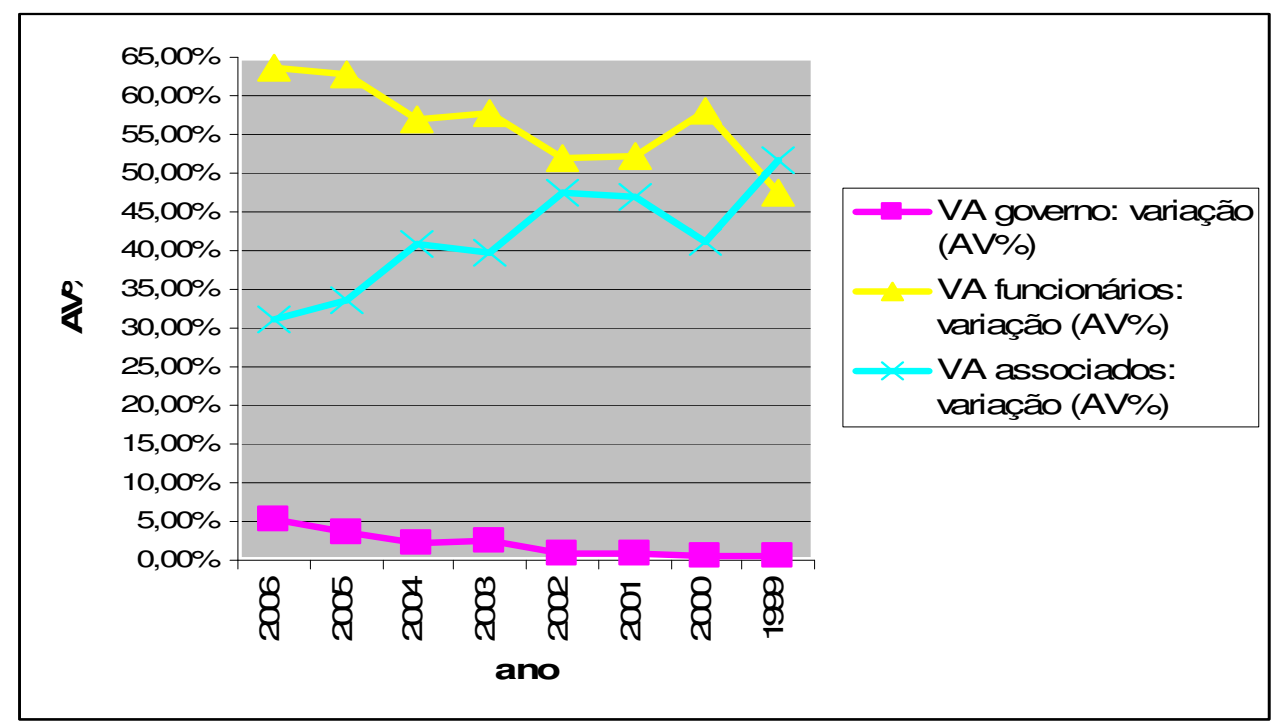

Gráfico 2 - Análise Vertical do VA destinado aos Governos, Funcionários e Associados com base no Valor Adicionado Total no período de 1999 a 2006.

Fonte - Cooperativa de Crédito de Livre Admissão de Associados Grande Santa Rosa 
A Demonstração do Valor Adicionado (DVA) como fonte de informações gerenciais: Um estudo em uma cooperativa de crédito.

Jair Antonio Fagundes, Marcos Rogério Rodrigues, Clébia Ciupak, Laura Sabbado da Rosa.

Estas análises sugerem que outras variáveis devam ser consideradas em futuros trabalhos, tais como: a) a quantidade de funcionários, para medir se o aumento na participação do VA é explicado pelo aumento da quantidade de funcionários; b) se o aumento do VA destinado ao governo é fruto ou não de aumento dos percentuais dos tributos ou criação de novos tributos; c) se o planejamento estratégico contempla esta diminuição na participação do VA das sobras aos associados.

\section{Considerações Finais}

A Contabilidade tem por finalidade contribuir para o processo decisório dos usuários das suas informações, na medida em que as demonstrações representam seu produto final devendo, portanto, traduzir da forma mais clara possível a realidade financeira, econômica e social das entidades. Nesse particular, os contadores devem estar comprometidos com melhorias no processo de comunicação contábil. A Demonstração de Valor Adicionado se perfila como um relatório de grande utilidade dentro do novo contexto sócio-econômico e que atende ao aspecto acima referido.

Nessa demonstração os dados evidenciam o processo de geração de riqueza por parte das entidades e a forma como esta riqueza é distribuída aos diferentes stakeholders, tendo-se elementos para analisar a movimentação de recursos bem como a sua evolução no tempo, análise esta acessível aos mais diversos usuários, dada a simplicidade com que se apresenta esta demonstração.

Apoiado num referencial teórico desenvolveu-se um estudo empírico tendo por base os dados obtidos nas Demonstrações Contábeis da Cooperativa de Crédito da Sicredi Grande Santa Rosa, no período compreendido entre 1999 e 2006, e a conseqüente apresentação das Demonstrações do Valore Adicionado mediante o emprego do método da adição e o enfoque contábil.

A elaboração da Demonstração do Valor Adicionado permitiu observar a riqueza gerada e como a mesma foi distribuída entre funcionários, governos e associados, comparando-os entre si (análise horizontal) e em si (análise vertical), analisando posteriormente as variações ocorridas nesta distribuição, visando contribuir para subsidiar o processo de tomada de decisões necessárias para um melhor gerenciamento e direcionamento dos negócios. 
A Demonstração do Valor Adicionado (DVA) como fonte de informações gerenciais: Um estudo em uma cooperativa de crédito.

Jair Antonio Fagundes, Marcos Rogério Rodrigues, Clébia Ciupak, Laura Sabbado da Rosa.

A oportunidade de estudar e analisar os reflexos da Demonstração do Valor Adicionado nesta entidade, permitiu que fossem geradas várias informações que podem ser úteis a diversos usuários, significando uma importante ferramenta de suporte à gerencia, de vez que até então as análises tinham unicamente como parâmetro os dados apresentados nas Demonstrações de Resultados do Exercício.

\section{Referências}

CONSELHO FEDERAL DE CONTABILIDADE. Demonstração do Valor Adicionado, Resolução no 1010 de 19/11/2004, disponível em , acesso em 30/08/2005.

COSENZA, J.P. 2003. A eficácia informativa da Demonstração do Valor Adicionado. . Edição especial, USP, São Paulo, ano XIV, p.7-29, out/2003.

GIL, A. C. 1999. . São Paulo, Atlas, 5a ed., 206 p.

KROETZ, C.E.S. 2000 . São Paulo, Atlas, 162p.

OLIVEIRA, A.S. e GARCIA, E.A.R. 2000. Demonstração do Valor Adicionado - uma contribuição da contabilidade para a mensuração da participação econômica e social da entidade empresarial.

XVI Congresso Brasileiro de Contabilidade. Goiânia, 12p.

RIBEIRO, O.M. $1999 . \quad$. São Paulo. Saraiva, 60 ed., 269p.

RODRIGUES, A.A. 1995.

. Brasília, 24(92):45-61.

SANTOS, A. e HASHIMOTO, H. 2003.

. São Paulo, Apostila. RAUSP, FEA/USP, 38(2):153-164.

SICREDI. Demonstrações Contábeis de 1999, 2000, 2001, 2002, 2003, 2004, 2005 e 2006. Disponível em http://www.sicredi.com.br, acesso em 10/06/2006.

TINOCO, J.E.P. 2001.

. São Paulo, Atlas, 243 p.

Submissão: 19/02/2008

Aceite: 01/04/2008 